\title{
New Type of Bimetal Composite Casting and Welding Connection Square Hammer
}

\author{
Penghui Yang ${ }^{1,}$, Shoufan Rong ${ }^{1, b}$, Xingming Zhao ${ }^{1}$, Yongchang $\mathrm{zhu}^{1}$, \\ Yanhe $\mathrm{wu}^{1}$, Xingyi $\mathrm{Li}^{1}$ \\ ${ }^{1}$ School of Materials Science and Engineering, Jiamusi University, Jiamusi, 154007, China \\ aemail: 987910162@qq.com, bemail: rsfzz@163.com(Corresponding author)
}

\begin{abstract}
Keywords: Square Hammer, Dual Liquid Bimetal, Composite Casting,Welded Connection
\end{abstract}
\begin{abstract}
The brick crusher hammers were used in factory, which wear-resisting was poorer. According this phenomenon, the single structure was designed in symmetrical fission structure. Firstly, high chromium cast and low alloy steel were casted into half of the bimetal hammer head, then two new type bimetal hammer head were connected into a whole body by the welding technology. The high abrasion resistance and impact toughness of bimetal composite material played an important role in process of use and the service life was improved effectively, which provided a new way of thinking for complex compound casting. The results showed that the new type of bimetal composite casting and welding connection hammer production's cost was 1.5 times of high manganese steel hammer, but the service life was improved 3 5 times. Low alloy steel and high chromium cast iron composite layer was a metallurgical combination, and the whole strength was good and no fault phenomenon in the using process after welding.
\end{abstract}

\section{Introduction}

The hammer head [1] was an important part of the hammer crusher, which used in bad working condition and the loss was big. The hammer head were almost casted into high manganese steel material. The head working condition is different, and this kind of material wear-resisting life generally was 12 24 hours, which can not satisfy the further requirement. If the better wear resistance materials were employed, such as high chromium cast iron and medium carbon alloy steel, they were prone to fracture due to poor toughness. And the technology adopted double liquid double metal composite casting, it could not form a shape at a time due to the first metal poured into the mold cavity was a plane.

Half of the hammer head was made respectively by using compound casting technology in this paper and then put two semi-finished products for welding with welding method in cast steel parts, at last combined into bimetal composite casting and welding connection type hammer.

\section{Structure design}

Original hammer of single material was shown in Fig.1, and the four hammer sides were the serious wear part at the work, the middle part is the support part and the middle hole is the assembly-hole. According to the liquid and liquid bimetal composite casting technology [2], there was a plane interface after the first metal poured into the mold cavity, so this hammer would be one-off double metal composite casting molding is impossible. The hammer head is divided into two halves of the same shape structure from the middle, then using multivariate high chromium cast iron material for the parts that were easy to be worn, and the support part adopted micro alloyed casting steel. Firstly, use bimetal composite casting process casting wear-resistant blocks shown as Fig.2, and then welding together the pieces of two wear-resisting in the cast steel parts shown in Fig.3. This design using the composite casting before welding method provided a new way for complex parts of bimetal casting, which can not only solve the problem of active hammer not wear-resisting, but also make the modeling simplifies, and needn't put sand core and simplifies the process for bimetal composite casting process, save the cost. 

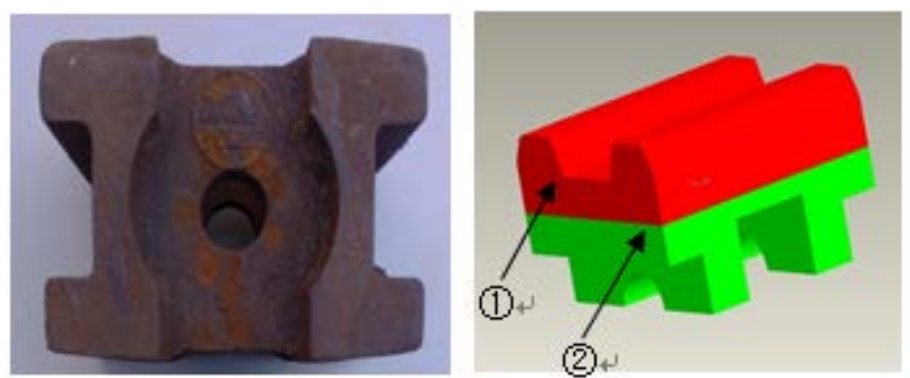

(1)High chromium iron (2)Low alloy steel

Fig.1. Original hammers Fig.2. Half of the hammer

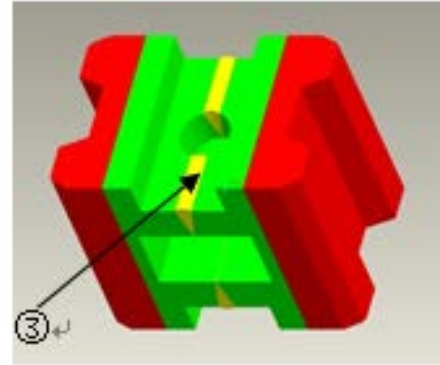

(3)Welding line

Fig.3. Complete hammer

\section{Preparation of double metal composite material}

High chromium cast iron material. Wear-ability of high chromium cast iron [3], mainly depends on the hardness of materials. The test chemical components were shown in Tab.1.

Tab.1. Chemical composition of the high chromium cast iron (wt \%)

\begin{tabular}{ccccccc}
\hline Designation & $\mathrm{C}$ & $\mathrm{Cr}$ & $\mathrm{Mo}$ & $\mathrm{Mn}$ & $\mathrm{B}$ & $\mathrm{Cu}$ \\
\hline Ordinary high chromium cast iron & $2.6 \sim 2.9$ & 24 & $0.5 \sim 1$ & $0.6 \sim 0.8$ & -- & $0.5 \sim 0.8$ \\
High carbon high chromium cast iron & 3.3 & 24 & 0.7 & 1.8 & 0.2 & 0.6 \\
\hline
\end{tabular}

Cast steel material. In order to prevent the brittle fracture in welding process, according to the requirement of the welding process of material, the cast steel chemical composition were designed as shown in Tab.2.

Tab.2. Cast steel chemical composition (wt \%)

\begin{tabular}{ccccc}
\hline $\mathrm{C}$ & $\mathrm{Si}$ & $\mathrm{Mn}$ & $\mathrm{P}$ & $\mathrm{S}$ \\
\hline 0.26 & 0.3 & 0.5 & $<0.1$ & $<0.03$ \\
\hline
\end{tabular}

Craft process. Using liquid-liquid double metal casting method cast steel and high chromium cast iron casting castings one by one after two kinds of metal melting into molten iron, and then welding connection in cast steel parts after cleaning, the final with heat treatment. Pouring technology was that low alloy steel iron liquid temperature is $1570 \mathrm{C}$ that is poured into the cavity of built, then the high chromium cast iron liquid was poured into the cavity at the temperature was 1520C after the surface of solidified completely. Heat treatment technology was that $980 \mathrm{C} \times$ $120 \mathrm{~min}$ air cooling and $200 \mathrm{C} \times 180 \mathrm{~min}$ tempering.

Testing equipment. The steel alloy melting in the intermediate frequency furnace which type is KGPS-800 100kg and $150 \mathrm{~kg}$ and the box type heat treatment furnace is RX-45-9, the test of impact at the automatic impact test machine which type is $\mathrm{ZBC}-300 \mathrm{~B}$ and the rock well hardness tester is $\mathrm{R}(\mathrm{D})-50 \mathrm{~A} 1$ and the metallographic analysis the used the optical microscope which type is Olympus GX71 and the part of cast steel used the ac arc welder that the type is BX1-160-1 etc.

\section{Result of the experiment and analysis}

High chromium cast iron. To form the new type of high carbon high chromium cast iron that increased the content of $\mathrm{C}, \mathrm{Mn}$ and $\mathrm{B}$ in common high chromium cast iron, and the mechanical properties as shown in Tab.3. From the table, the new type of high carbon high chromium cast iron hardness was increased obviously than ordinary high chromium cast iron, and the toughness was unchanged basically. Carbon [4] was an important component of the carbide. The increased amount of carbon made the number of primary carbide and the hardness increase. The primary carbide exists had split effect on high chromium cast iron matrix, which leaded to new type of high carbon high chromium cast iron toughness decreased. Mn [5] has a strong role in promoting for harden-ability, and can neutralize the harmful effect of S. Increased the content of Mn, can increased hardness obviously. B [6] can increased harden-ability obviously, and increased its content, the hardness improved, and the impact toughness was dropped. 
Tab.3. Technical properties of the high chromium cast iron

\begin{tabular}{ccc}
\hline Designation & $\alpha_{\mathrm{k}}\left(\mathrm{J} / \mathrm{cm}^{2}\right)$ & HRC \\
\hline Ordinary high chromium cast iron & $3.5 \sim 4.5$ & $60 \sim 62$ \\
high carbon high chromium cast iron & 3.5 & 64 \\
\hline
\end{tabular}

Fig.4 was the metallographic contrasted figure for the two kinds of high chromium cast iron, in which long white strip is first eutectic carbides. As is seen that white long strips of tissue in Fig.4.b is more than the Fig.4.a, which shows that the number of eutectic carbides in new type of high chromium cast iron is increase. White granular is granular carbides, and the matrix can be protected by those carbides, so the impact toughness of high carbon high chromium cast iron was not too low. According the analysis and calculation, the total number of carbide in high carbon high chromium cast iron from ordinary high chromium cast iron 30\% 35\% increased to 40\% 42\%, the increasing of the carbide made the hardness and the wear resistance increased significantly.

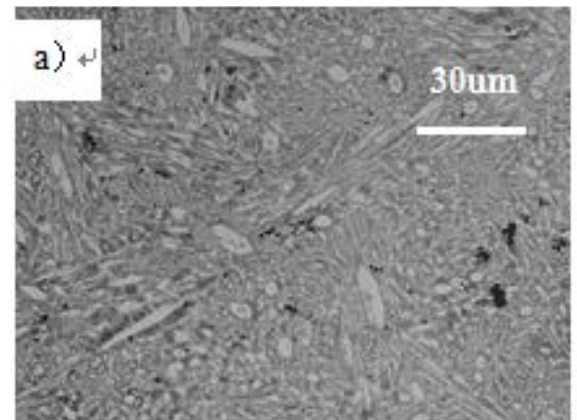

(a) Ordinary high chromium cast iron

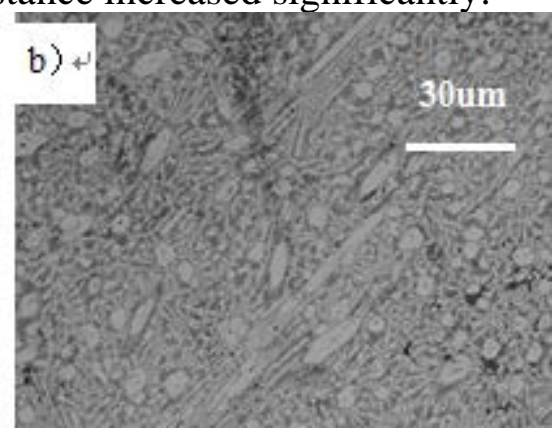

(b) High carbon high chromium cast iron

\section{Double liquid double metal composite technology.}

Fig.4. High chromium cast iron metallographic contrast figure

Low alloy steel was poured into mold cavity first, then poured fluid of high temperature and high chromium cast iron after the surface frozen completely. A thin layer of solid low alloy steel can be melt by high chromium cast iron melt heat. Interface constitution diagram as shown in Fig.5.

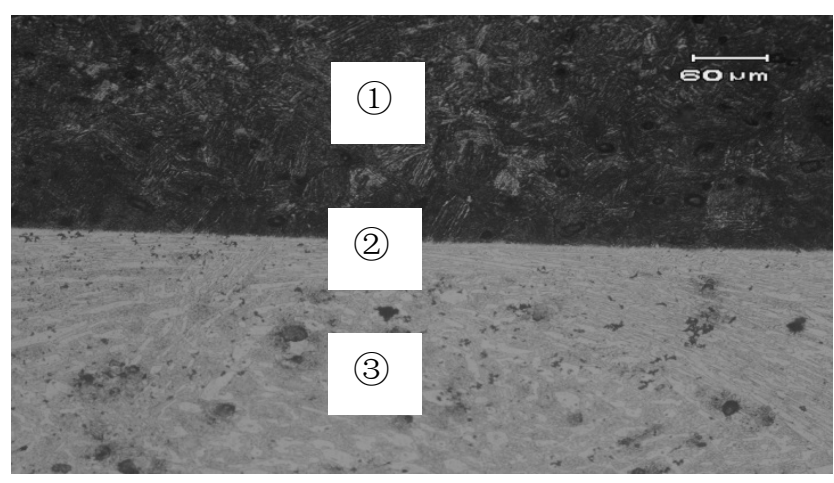

(1)Low alloy steel (2)Composite interface (3)High-chromium iron

Fig.5. Composite interface metallographic figure

A clear composite interface was formed due to the corrosion resistance of steel materials different. Low alloy steel quenching tempering organization at upper is composed of ferrite and pearlite. High chromium cast iron quenching tempering organization at underside is isolates distribution in continuous martensitic matrix as $(\mathrm{Cr}, \mathrm{Fe})_{7} \mathrm{C}_{3}$ carbide. A jagged interface bonding area with a micro interface distributed among the interface. From the interface can be seen that liquid-liquid double metal occurred molten metal and mutual penetration in the process of formation and combination in metallurgical. The bonding area without micro defects such as cracks, gas holes and scab etc, which shows that the composite interface combination is good.

Trial installation. Installed test was conducted in Hegang brick factory. The result show that the new hammer service life increased 3 5 times compared with ordinary single material of high manganese steel and the production cost is 1.5 times of the high manganese steel hammer, which not only improves the production efficiency, but also has make a great contribution to the words of energy conservation and emissions reduction, low carbon environmental protection. The net weight of a hammer head is $12 \mathrm{~kg}$, the total power consumption is 20 degrees and the emission of $\mathrm{CO}_{2}$ is $17 \mathrm{~kg}$. This kind of crusher hammers were used in brick factory, and the annual consumption was 
200000 tons. A new type of hammer head could take the place of four high manganese steel hammers, which could save 150000 tons metal, 250000 degrees power and reduced the emissions of $\mathrm{CO}_{2}$ saved the steel resources and reduced the electric energy consumption, but also reduced the labor 212500 tons. The replacement cycle of the hammer head is extended and the work intensity of the workers is reduced while increased the life expectancy. It can be saved the time for replacing hammer head three times in a working cycle and improve the efficiency of the crusher. Not only intensity of workers and improved the production efficiency. Fig.6 is the high manganese steel hammer contrast figure. Fig.7 is the new hammer contract figure.

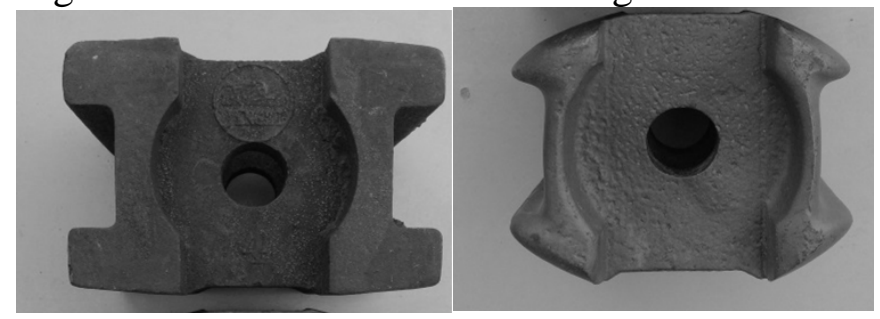

Fig.6. Comparison before and after the use of the high manganese steel

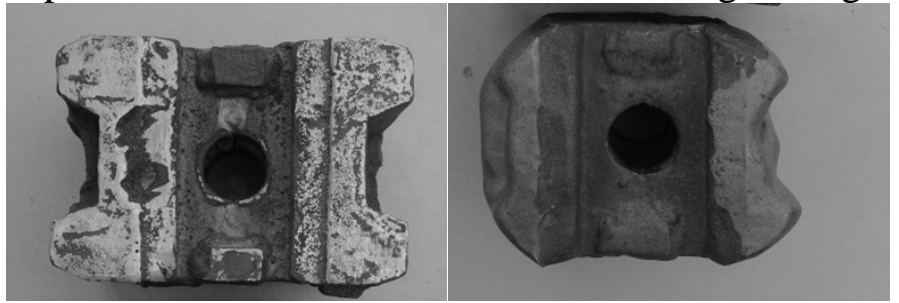

\section{Conclusions}

Fig.7. New hammer contrast figure before and after use

(1)A new type of hammer head are produced based on liquid-liquid bimetal composite casting technology, and the low alloy steel and high chromium cast iron composite layer have reached the metallurgical combination and the strength on the whole head was good after welding. There was no fracture phenomenon in using.

(2) Compared with high carbon high chromium cast iron and ordinary high chromium cast iron, the ductile basically unchanged, but the hardness is increased more than 4 times and the wear resistance is increased significantly.

(3) New type of bimetal composite casting and welding connection square hammer production cost is 1.5 times of a single material of high manganese steel hammer, but the using life is improved $3 \sim 5$ times. And it saved energy, improved the efficiency and go with the development strategy that the words of energy conservation and emissions reduction, low carbon environmental protection.

\section{Acknowledgements}

This work was sponsored by the national natural science foundation of China (project No. 51371090) and the President entrepreneurial innovation fund of Jiamusi University (project number xzyf2013-05) and the graduate student innovation of science and technology of Jiamusi University (project LZR2014-007) .

\section{References}

[1] Jianbing Chao, Hanguang Fu. The research and application of high chromium cast iron hammer head [J]. Journal of coal mine machinery.2005: 17-19.

[2] Hongxiao Cheng, Chao Wang, Weidong Shen. The hammer head bimetal composite casting process [J]. Device and technique of casting of China. 2004: 32-34.

[3] Chen Liu, Baoliang Pan, High chromium cast iron pieces of production and application of technology review [J], Yunnan metallurgy. 2006: 85-93

[4] Shoufan Rong, Jiwei Guo. Double liquid bimetal composite casting hammer hammer production process. China patent, 200710071731[P]. 2008: 08-13

[5] Rongjun Zhang, Jian-bing Chao. Manganese effect the performance of Cr15MnV cast iron group [J]. Journal of hot working process, 2007: 8-10 
[6] R. Correa, A. Bedolla-Jacuinde. Effect of boron on the sliding wear of directionally solidified high-chromium white irons. Wear [J]. 2009: 495-504 